\title{
Intoxicação crônica por cobre em ovelhas pastoreadas em pomar de videiras adubado com cama aviária
}

Luiz Alberto Oliveira RIBEIRO'

Norma Centeno RODRIGUES 2

Willian Augusto SMIDERLE ${ }^{3}$

\section{${ }^{1}$ Correspondência para:}

Luiz Alberto Oliveira Ribeiro, Departamento de Medicina Animal, Faculdade de Veterinária-UFRGS

Av. Bento Gonçalves, 9090, Porto AlegreRS 91540-000, e-mail: berto@ufrgs.br

Recebido para publicação: 03/10/2005 Aprovado para publicação: 23/04/2007

\author{
1 - Departamento de Medicina Animal, Faculdade de Veterinária - UFRGS, \\ Porto Alegre - RS \\ 2 - Faculdade de Veterinária, ULBRA, Canoas - RS \\ 3 - Médico Veterinário, acadêmico de Mestrado, Faculdade de Veterinária - \\ UFRGS, Porto Alegre - RS
}

\section{Resumo}

No presente trabalho é relatado caso de intoxicação crônica por cobre (ICC) ocorridos em rebanho ovino pastoreados em pomar de videiras, na serra Gaúcha; suplementados com bagaço de uva e concentrado. O pomar era aspergido anualmente com solução de sulfato de cobre a $2 \%$ e teve seu solo adubado com cama aviária. Os ovinos mostraram andar cambaleante, icterícia intensa das mucosas e urina escura, dos quais foram a óbito oito animais, correspondendo a 57\% do total do rebanho. Os sinais clínicos e lesões histológicas foram características da ICC. A dosagem de Aspartato Aminotrasferase (AST) no soro dos seis ovinos remanescentes variou de 48,8 a 403,3 UI/L. O nível de cobre encontrado na cama aviária, bagaço de uva, pastagem e concentrado foram de 637, 158, 86 e $18 \mathrm{mg} / \mathrm{kg}$ respectivamente. Conclui-se que os óbitos ocorreram devido ao alto nível de cobre encontrado na pastagem, bagaço de uva e concentrado administrado aos animais. Sugere-se também, o risco de dano ambiental no uso de cama aviária na adubação de pastagem, assim como a inadequação da alimentação de ovinos com bagaço de uva.

\section{Introdução}

A introdução de ovinos em pomares de macieiras, pessegueiros e nogueiras vem sendo realizada no Rio Grande do Sul (RS). Nesse tipo de integração, o ovino diminuiria os custos de limpeza do pomar e ainda contribuiria fertilizando a terra com suas fezes e urina. Nos pomares, o controle periódico de pragas é realizado com produtos a base de cobre que leva ao acúmulo desse elemento na pastagem. No Estado, foi relatado casos de intoxicação por cobre, em ovinos, pastoreados em pomar de macieira. A concentração de cobre encontrada na pastagem foi de $60 \mathrm{mg} / \mathrm{kg}^{1}$.

Os ovinos, diferentemente de outras espécies, não toleram regimes alimentares que contenham mais de $10 \mathrm{mg} / \mathrm{kg}$ de cobre.
A absorção do cobre, nessa espécie, é regulada principalmente pelo molibdênio. No RS, os solos e pastagens contêm entre 5 - $10 \mathrm{mg} / \mathrm{kg}$ de cobre $^{2}$, e não mais que 0.2 $0.3 \mathrm{mg} / \mathrm{kg}$ de molibdênio ${ }^{3}$ estando esse elemento em condições limítrofes para obstaculizar a absorção do cobre da pastagem. No Reino Unido, foram descritos surtos de intoxicação por cobre em ovinos criados em pastagens que foram adubadas com fezes de suínos. Tais dejetos podem conter valores acima de $600 \mathrm{mg} / \mathrm{kg}$ de cobre tornando desaconselhável seu uso para pastagens de ovinos ${ }^{4}$.

No presente trabalho, são apresentados dados sobre casos de intoxicação por cobre ocorridos em ovinos mantidos em pomar de videiras, na serra gaúcha. O pomar foi aspergido com produto a base de cobre e o solo adubados com cama aviária. 


\section{Material e Método}

Histórico clínico - em uma propriedade da região serrana do RS foram introduzidos 14 ovinos adultos, sem raça definida, com o objetivo de controlar o crescimento da pastagem em um pomar de videiras. O pomar era aspergido anualmente com sulfato de cobre a $2 \%$, para controle de pragas e o solo foi adubado com cama de aviário.

Necropsia e exames laboratoriais dois animais foram necropsiados a campo, quando foram colhidos fragmentos de fígado e rins para exame histopatológico. Esses materiais foram fixados em solução tamponada de formol a 10\%, incluídos em parafina, cortados a uma espessura de cinco micrômetros e corados pela técnica de Hematoxilina/Eosina (HE) e pelo método de Uzman para cobre ( ácido rubeânico) ${ }^{5}$.

Exame toxicológico - amostras da pastagem de vários pontos do pomar foram coletadas, reunidas em uma amostra única e submetida a análise de cobre por espectofotometria de absorção atômica. Foi também tomada amostra da cama de aviário usada como adubo, assim como do bagaço de uva e ração administrados como suplementação alimentar aos ovinos. Essas amostras foram também enviadas para dosagem de cobre pelo mesmo método mencionado anteriormente.

Exame bioquímico - amostras de sangue de seis ovinos foram coletadas, deixadas coagular à temperatura ambiente, sendo retirado o coagulo e preservado o soro em refrigeração a $4{ }^{\circ} \mathrm{C}$. As amostras de soro assim obtidas foram usadas para dosagem de Asparato Aminotrasferase (AST) usando reflotron Boehringer Mannhein.

\section{Resultados}

Dados clínicos coletados a campo os ovinos examinados mostraram andar cambaleante, icterícia intensa, urina escura e morte. Do total de 14 ovinos da propriedade morreram oito, correspondendo a $57 \%$ do rebanho. O regime alimentar dos animais além do pastoreio no pomar de videiras incluía suplementação com bagaço de uva ad libtum e $200 \mathrm{~g}$ de concentrado por ovino/ dia.

Achados de necropsia - o exame interno mostrou icterícia generalizada, fígado amarelado, rins aumentados de volume e escuros. A bexiga continha urina de cor escura achocolatada tendo sido observado na cavidade abdominal acúmulo de líquido sanguinolento.

Exames histopatológicos - no fígado, foi observado degeneração dos hepatócitos, alguns deles mostrando-se aumentados de tamanho com a presença de vacúolos no citoplasma, em alguns casos chegando a deslocar o núcleo para a periferia da célula; necrose hepática predominantemente na região periacinar, fibroplasia periportal com discreta proliferação dos ductos biliares, e pigmentos de coloração acastanhada no interior das células de Kupffer também foram verificados.

Os rins evidenciaram congestão, degeneração e necrose do epitélio tubular e a presença de inúmeros cilindros granulares de coloração vermelho-escura no interior dos túbulos remais. A coloração pelo ácido rubeânico demostrou a presença de grânulos positivos para cobre no interior das células de Kupffer e de hepatócitos necróticos.

Exame toxicológico - a dosagem de cobre nas amostras de cama aviária, Tabela 1 - Níveis de cobre em amostras de pastagem e suplementos alimentares administrados a ovinos mantidos em pomar de videiras na serra Gaúcha, 2005

Amostra

Cobre (mg/kg)

Cama aviária 637

Bagaço de uva 158

$\begin{array}{cc}\text { Pastagem } & 86 \\ \text { Ração } & 18\end{array}$

bagaço de uva, pastagem e ração são mostradas na tabela 1. Valores altamente tóxicos para ovinos foram encontrados nas amostras examinadas.

Dosagem enzimática - Os níveis de 
AST no soro dos seis ovinos coletados são mostrados na tabela 2. Nos seis ovinos sobreviventes os níveis de AST mostraram valores entre 48,8 e 403,3 UI/L, sendo que em $50 \%$ dos animais examinados o nível dessa enzima estava acima do normal.

\section{Discussão}

Embora a intoxicação por cobre no RS tenha sido diagnosticada, principalmente em ovinos preparados para exposições, submetidos a alimentação com concentrados, relatos têm chamado atenção para o risco dessa intoxicação em ovinos alimentados de outra forma ou pastoreados em áreas de risco. Ribeiro et al. ${ }^{1}$ descreveram a morte de 21 ovelhas, correspondendo a 17,5\% do rebanho, pastoreadas em pomar de macieiras aspergido com sulfato de cobre. O nível de cobre encontrado na pastagem foi de 60 $\mathrm{mg} / \mathrm{kg}$. Mais recentemente foram registradas perdas de ovinos alimentados com cama aviária e polpa cítrica, que mostraram conter 171 e $40 \mathrm{mg} / \mathrm{kg}$ de cobre 6 .

No presente trabalho é descrita a morte de mais de $50 \%$ de um rebanho ovino mantido em pomar de videiras. O nível de cobre na pastagem do pomar foi de $86 \mathrm{mg} /$ $\mathrm{kg}$, maior do que o encontrado sob pomar de macieiras. No caso aqui descrito, o pomar, além de ser aspergido com sulfato de cobre, teve seu solo adubado com cama aviária que contém alta concentração desse metal. Essa prática certamente contribuiu para aumentar o nível de cobre encontrado na pastagem.

$O$ inquérito realizado na propriedade revelou que o rebanho ovino foi suplementado com ração e bagaço de uva. A ração administrada era formulada para bovinos contendo $18 \mathrm{mg} / \mathrm{kg}$ de cobre, valor tóxico para ovinos. Acrescente-se que o bagaço de uva oferecido ad libitum às ovelhas, mostrou concentração de cobre altamente tóxica para essa espécie. Assim, se por um lado a asperção do pomar com cobre e a adubação do mesmo com cama aviária elevaram o nível desse metal na pastagem, por outro lado, a suplementação com bagaço de uva e concentrado, aumentou ainda mais a ingestão diária de cobre pelo rebanho, ultrapassando largamente a tolerância da espécie. A AST no soro dos ovinos remanescentes mostrou níveis bem acima do normal, sugerindo que esses animais poderiam, em breve, entrar em crise hemolítica típica dos casos de intoxicação por cobre sugerido por Ross ${ }^{7}$.

A criação de ovinos na serra Gaúcha é bastante rara. No caso aqui relatado, os proprietários haviam introduzido ovinos para reduzir o inço no pomar e diminuir o uso de agrotóxicos. Entretanto, o desconhecimento técnico da sensibilidade dessa espécie ao cobre e a alta contaminação ambiental causada pelo uso da cama aviária como adubo, certamente contribuíram para as perdas observadas. Os dados aqui relatados alertam para os riscos ambientais do uso de cama de frango, seja como alimento para ruminantes, ou como adubo de pastagens que serão futuramente usadas por ovinos. De outra parte, o alto nível de cobre encontrado no bagaço de uva não recomenda o uso desse subproduto para alimentação de ruminantes.

Tabela 2 - Níveis de Aspartato Aminotrasferase (AST) no soro de ovinos mantidos em pomar de videiras na serra Gaúcha, 2005

\begin{tabular}{cc}
\hline Ovino & AST (UI/L) \\
\hline 01 & 403,3 \\
02 & 323,9 \\
03 & 151,0 \\
04 & 55,0 \\
05 & 54,9 \\
06 & 48,8 \\
\hline Média & 172,8 \\
\hline
\end{tabular}




\section{Chronic copper poisoning in sheep grazed under grape orchard fertilise with poultry litter}

\begin{abstract}
This work describe dead due to chronic copper poisoning (CCP) that occurred in a flock of sheep grazed under grape orchard, located at the hilly area of southern Brazil; supplemented with concentrate and crushing grapes husks. The orchard was annually sprayed with 2 per cent copper sulphate and the ground fertilised with poultry litter. The sheep showed depression, jaundice and hemoglobinuria. Fourteen sheep died, representing 57 per cent of the flock. The clinical sign, necropsy and microscopic findings were typical of CCP. The serum level of aspartate aminotrasferase (AST) of remain six sheep, varied from 48.8 to $403.3 \mathrm{IU} / \mathrm{L}$. The cooper level found in the poultry litter, crushing grapes husks, grass and concentrate were 637, 158, 86 and 18 $\mathrm{mg} / \mathrm{kg}$, respectively. It is concluded that the sheep losses occurred due to the high level of copper found in the pasture, crushing grapes husks and concentrate fed to the animals. It is also suggested, the environmental risk of poultry litter as fertiliser of sheep pasture as well as the use of crushing grapes husks as sheep supplemental feeding.
\end{abstract}

Key words: Sheep. Chronic copper poisoning. Poultry litter. Crushing grapes husks.

\section{Referências}

1 RIBEIRO, L. A. O. et al. Intoxicação crônica por cobre em ovinos mantidos em pomar de macieiras. Pesquisa Veterinária Brasileira, v. 15, n. 1, p. 15-17, 1995.

2 CAVALHEIRO, A. C.; TRINDADE, D. S. Os minerais para bovinos e ovinos criados em pastejo. Porto Alegre: Sagres DC Luzzato, 1992. 142 p.

3 GAVILLON, O.; QUADROS, A. F. F. Levantamento da composição mineral das pastagens nativas do RS: o cobre, o cobalto e o molibdênio. In: CONGRESSO INTERNACIONAL DE PASTAGNES, 9.,1966, São Paulo. Anais... São Paulo: [s.n.], 1966. p. 709-712.

4 UNWIN, R. J. Copper in pig slurry: some effect and consequences of spreading on grassland. In: Inorganic pollution and agriculture. London: $\overline{\text { Ministry }}$ of Agriculture, Fisheries and Food, 1980. p. 306-319.

5 LUNA, L. G. Manual of histology staining methods of the armed force institute of pathology. New york: mc graw-hill, 1968. p. 178.

6 RODRIGUES, N. C.et al. Chronic copper poisoning in sheep fed with poultry litter and citrus pulp. ARS Veterinária, v. 20, n. 2, p. 175-179, 2004.

7 ROSS, D. B. The diagnosis, prevention and treatment of chronic copper poisoning in housed lambs. British Veterinary Journal, v. 122, n. 7, p. 279-284, 1966. 